ARBOR Ciencia, Pensamiento y Cultura Vol. 188 - 755 mayo-junio (2012) 515-527 ISSN: 0210-1963 doi: 10.3989/arbor.2012.755n3005

\section{CIUDADANÍA Y ESPACIO PÚBLICO EN LA ERA DE LA GLOBALIZACIÓN NEOLIBERAL*}

\author{
Jorge Sequera \\ Universidad Complutense de Madrid \\ Michael Janoschka \\ Universidad Autónoma de Madrid
}

\section{CITIZENSHIP AND PUBLIC SPACE IN THE AGE OF NEOLIBERAL GLOBALIZATION}

\begin{abstract}
The profound economic, social and political reforms in contemporary migration societies are seriously tackling the scope of civil, social and political rights of citizenship. In this article, we refer to the concept of citizenship through four dimensions that enlarge its theoretical content and transcend the historical rationality of rights, duties and the State: (a) citizenship as a collective subject that is being permeated by (neoliberal) logics of producing urban spaces; (b) citizenship as a power relation expressed by politics of scale; (c) citizenship as a discursive mechanism that articulates identity and place through politics of belonging; and (d) citizenship interpreted through acts that challenge the multiple dimensions of domination. This conceptualisation helps to outline the conceptualisation of acts of citizenship that demand a re-appropriation of public space and, in general terms, the public sphere, aiming at constructing new spaces of citizenship.
\end{abstract}

KEY WORDS: Citizenship; neoliberal globalization; public space; politics of place; politics of scale; politics of identity; activist citizenship.

\section{Discursos de CIUdAdANÍA - UNA INTROdUCCIÓN}

El concepto de ciudadanía es controvertido, y en las dos últimas décadas los estudios sobre este concepto han provocado importantes discusiones desde perspectivas culturales, antropológicas, geográficas y políticas. Algunas de las ideas tradicionales, como las planteadas por el sociólogo británico Thomas Marshall (1997), que se centran principalmente en los derechos (políticos, civiles y sociales) y deberes ciudadanos que están sujetos a una comunidad política y territorial determinada, han sido impugnadas y en cierta medida reemplazadas. Entre otros, este cambio conceptual responde a algunas de las principales tendencias dentro de los Estados-nación occidentales, que incluyen las reivindicaciones de participación como aspectos fundamentales de las políticas democráticas y democratizadoras. Este tipo de resistencia se basa al
RESUMEN: Las profundas reformas en las condiciones económicas, sociales y políticas actuales están afectando gravemente el alcance de los derechos civiles, sociales y políticos de la ciudadanía. Un concepto, el de ciudadanía, que es atravesado por las lógicas neoliberales de producción del espacio público así como por la lógica histórica Derecho-Deber-Estado. Pero este mismo concepto de diudadanía puede ser analizado desde tres novedosos aspectos teóricos que amplien su dimensión y superen los anteriores: (a) la ciudadanía como una relación de poder que se expresa mediante políticas de escala; (b) la ciudadanía como mecanismo discursivo que articula identidad y lugar a través de las políticas de pertenencia; $y_{\text {, }}$ (c) la ciudadanía interpretada a través de actos que desafian las múltiples relaciones de dominación. Estas tres dimensiones nos ayudarán a comprender los actos de ciudadanía que demandan la reapropiación de la esfera y del espacio público con el fin de construir nuevos espacios de ciudadanía.

PALABRAS CLAVE: Ciudadanía; globalización neoliberal; espacio público; esfera pública; políticas de lugar; políticas de escala; políticas de identidad; ciudadanía activista.

mismo tiempo en la identidad y la diferencia, tratando de definir ciudadanía sin relacionarla necesariamente con el estatus de autoridad que ejerce un Estado.

En este artículo, queremos dirigirnos al término desde la variedad de luchas políticas existentes, siguiendo el concepto de 'lucha política' (derivado del término inglés de 'contentious politics'; Tilly y Tarrow 2007), estrechamente relacionado con la ciudadanía, la identidad y la pertenencia, así como con el espacio, es decir, con los discursos y las dimensiones espaciales de las relaciones sociales. Como Leitner et al. (2008: 157) sugieren, el concepto de contentious politics se utiliza para describir el fenómeno de la resistencia social organizada contra las normas hegemónicas, en el que participantes de diferente condición se unen para desafiar a los sistemas dominantes, a la autoridad, con el fin de promover imaginarios alternativos. 
En este sentido, es interesante analizar cómo los conflictos habitan ya en espacios políticos fuera del marco nacional y tienen un escenario más amplio, en el que se incluyen una serie de instituciones y una variedad de escalas geográficas (Routledge 2008: 336). De esta forma, se argumenta que las identidades políticas son negociadas a través de múltiples escalas, lo que convierte su interpretación en un verdadero reto para la teoría política y para la geografía que estudia la acción política colectiva, siendo el espacio de la ciudad, como escenario predilecto de las luchas, mucho más completo y complejo para la política que el del Estado (Sassen 2003: 39). Incluye, entre otros aspectos, las políticas de identidad (y de diferencia), las políticas de lugar y las políticas de escala que pueden ser analizadas desde la acción y la lucha política. Esta perspectiva ayudará a desarrollar conceptualmente la cuestión central que se discutirá en este texto, es decir, el interés de explorar lo que se llama "ciudadanía" a través de algunos de los significados espaciales que expresa y alberga este controvertido concepto. El enfoque responde a las demandas teóricas de Lepofsky y Fraser (2003), que argumentan que el aumento de la flexibilidad en el uso práctico del concepto de ciudadanía debe ir de la mano de una transformación en su proyección teórica. Para abordar esta cuestión, vamos a revisar algunos de los discursos centrales en los estudios sobre ciudadanía. Siguiendo a Engin Isin (2009), tres importantes debates se pueden distinguir:

- En primer lugar, las numerosas discusiones que se producen con respecto a la pregunta de si la ciudadanía debe ser evaluada como un estatus o como una práctica. La ciudadanía como estatus responde a la perspectiva tradicional centrada en el Estado, donde la forma de adquirir los derechos de ciudadanía es discutida por los teóricos del Estado, en cuestiones como las leyes de extranjería, donde se regula la entrada, la estancia, los derechos y las libertades de los migrantes. Por otro lado, la ciudadanía entendida como práctica se centra en cuestiones tales como las políticas de integración, diversidad, participación, educación y transnacionalidad.

- En segundo lugar, la ciudadanía puede ser evaluada como elemento de dominación o como elemento de empoderamiento. La primera perspectiva se centra en las relaciones de poder y en la hegemonía de clase que se reproduce a través de la ciudadanía, limitando el concepto a una estrategia de dominación aplicada desde las clases do- minantes para expresar las prácticas de estratificación social a través de la institución Estado. En oposición a esto, los teóricos de los movimientos sociales se centran en la ciudadanía como la capacidad de los individuos y grupos a criticar y emanciparse de la política mediante la acción colectiva, como expresión del poder transformador de normas y políticas. Ambas posiciones, con líneas aparentemente claras y diferenciadas, se presentan realmente como difusas, al entender que la ciudadanía al mismo tiempo puede ser dominadora y creadora de espacios de autonomía.

- Un tercer debate se genera a partir del papel de la globalización neoliberal, que implica la creciente transnacionalización de nuestras relaciones sociales y transforma lo que se entiende por ciudadanía. Con respecto a este punto, es comprensible que si bien la globalización inicia transformaciones severas, el Estado-nación sigue siendo un actor central y un marco de referencia importante para la ciudadanía. Sin embargo, los debates sobre la ciudadanía post-nacional, la ciudadanía de la UE o la ciudadanía cosmopolita pueden ser un atractivo marco para repensar esta noción (Janoschka 2010). El centro de atención está puesto en las instituciones supranacionales, que generan nuevos interrogantes en la lógica de la ciudadanía nacional, ya que los sujetos ahora son atravesados por múltiples territorialidades: la ciudad, el Estado, la UE, los derechos humanos universales, etc.; por lo que se convierte en un proyecto normativo más complejo, en el que la globalización y los derechos humanos amplían el abanico de discursos y las reivindicaciones sobre los derechos de ciudadanía (Sassen 2003: 99).

Los debates de estos tres aspectos continúan, porque como Isin (2009) nos recuerda, han surgido nuevos actores, lugares y escalas que complejizan el estudio de la ciudadanía, más allá de los procesos migratorios. Por ejemplo, diferentes actores articulan sus reivindicaciones a través de nuevos sitios que están atravesados por múltiples y solapadas escalas de derechos y obligaciones. Como se argumenta en este artículo, ese enfoque transforma la concepción de la política, así como las políticas de ciudadanía, pudiendo cambiar la manera en que se comprenden las leyes, las reclamaciones, las herramientas de construcción de la nación y los ideales democráticos (Staeheli 2011). En este sentido, el texto analizará la interacción entre lugar, escala, identidad y ciudadanía con el fin de examinar crí- 
ticamente la espacialidad inherente de la acción política en las luchas por el reconocimiento de los derechos de una sociedad migrante ${ }^{1}$ en la era de la globalización neoliberal. A partir de pensar las relaciones entre políticas de lugar, escala e identidad, se irá desarrollando un marco teórico que entienda la ciudadanía como una categoría práctica que se expresa a través de sitios y actos específicos y que por tanto debe ser constantemente actualizada. Las demandas relacionadas con la participación política y social son importantes, y como parte de los derechos de ciudadanía, serán entendidas como una experiencia práctica de pertenencia e identidad. Esto tiene consecuencias sobre la forma de pensar las geografías políticas, como resultado de la intersección de los procesos de globalización y de movilidad. Al mismo tiempo que la ciudadanía se legitima bajo identidades políticas y prácticas de pertenencia específicas, nuestra perspectiva quiere añadir su dimensión espacial inherente para abrir nuevas narrativas en materia de acción política, en lo que entendemos como sociedad migrante. Para ello, re-conceptualizar la ciudadanía puede ser una buena fórmula para producir una mejor comprensión de la multiplicidad y simultaneidad de las prácticas, las identidades y las escalas dentro de la acción política colectiva, fijadas hasta ahora en la simple adhesión a un Estado-nación o a una comunidad espacialmente delimitada por la secuencia gobierno-territorio-población.

\section{LA PRODUCCIÓN DEL ESPACIO URBANO EN LA ERA NEOLIBERAL: LA MERMA DE ESFERA Y ESPACIO PÚBLICO}

Un aspecto central de la política urbana en la era neoliberal son las nuevas reglas, regulaciones, programas y micro-políticas que, siempre desde una perspectiva económica, ponen la ciudad en valor. La consecuencia de esa gestión es una reorganización de la política urbana según los principios y las dinámicas de la administración privada y capitalista que incluye la desregulación y la privatización de servicios urbanos básicos (Janoschka 2011). Esta relación queda patente en la reorganización espacial que han padecido las ciudades y que ha sido un amplio tema de debates en el campo de la geografía urbana y los estudios urbanos. Dada la larga lista de objeciones a ese modelo espacial, aquí apuntaremos principalmente las que redefinen las relaciones de poder que han surgido en las ciudades a partir de la implementación del modelo neoliberal. Siguiendo a Harvey (1996), podemos conceptualizar los espacios urbanos, los lugares construidos y las aglomeraciones como un resultado de las estrategias de poder en sí mismo, de discursos y luchas que se transmiten de forma materializada y simbólica a la vez.

Si a esta interpretación le unimos la relación cada vez más estrecha entre consumo y vida urbana, observamos que las distintas prácticas de consumo en la metrópolis son el nuevo eje primordial del proceso de producción y reproducción social (Alonso, 2004). Esta producción simbólica depende de los sentidos y valores que cada grupo socia otorgue a dichas actividades de consumo. Su dimensión no depende de una construcción azarosa del gusto, sino que parte de una construcción social del sentido del uso. Un consumo por tanto de los espacios públicos que se construye de manera desigual y conflictiva, generado por una apropiación específica de grupos sociales con distintos capitales (culturales, económicos, simbólicos). Estas lógicas mercantilizadoras son simultáneamente productoras y reproductoras de la estructura social (posición social), capaces de segregar tanto en tiempos como en espacios (urbanos) similares.

Según Aramburu (2008) el espacio público es un concepto urbano -configurado por las calles, plazas y parques de una ciudad-y político al mismo tiempo, es decir, la esfera pública en la cual la deliberación democrática es posible. Asimismo, podemos definirlo también siguiendo a Borja (2003), por su utilidad social de uso y acceso, haciendo que nos encontremos ante paradojas tales como el acceso restringido a lugares públicos o viceversa, el acceso abierto a establecimientos privados. Pero bajo la acepción liberal de espacio público, donde aparentemente éste es de "todos" por igual, se esquiva una realidad palpable, esto es, las diferencias de uso y las restricciones a determinados grupos sociales. Por lo que las relaciones de sociabilidad quedan condicionadas por el tipo de acceso y de uso que se den en estas plazas y calles, y por la delimitación de estos encuentros sociales cada vez más a lugares privados o privatizados. Como nos aclara Delgado (2011: 9) el espacio público se ha convertido en un vacío que existe entre construcciones y que debe llenarse de acuerdo con los objetivos de promotores y gobiernos, es decir, como espacios asépticos que aseguren sus conceptos de utilidad, seguridad y control. En este sentido, destaca el hecho de 
que se hayan institucionalizado diferentes formas de 'supuestas' políticas de prevención que incluyen la vigilancia (p. ej. por circuitos cerrados de videocámaras y televisión), el nuevo diseño de espacios urbanos y la organización del control social.

Descendiendo ahora sobre el terreno, pasando de los procesos de reconfiguración a los resultados, es posible observar que el espacio público deja de serlo un poco más cada día que pasa. Así proponemos que nos encontramos ante un paisaje urbano plagado de herramientas capaces de limitar y hacer exclusivo el uso de lo público. La maquinaria urbana tiene maneras muy sutiles de aplicar políticas de expulsión mediante segregación de uso o el control de los movimientos en dichos espacios. Como veremos a continuación, el espacio público en los países europeos está siendo cada vez más regulado, tratando de evitar usos "alternativos" o en muchos casos los que hasta ahora eran usos tradicionales y culturales del mismo y creándose o afianzándose espacios excluyentes, espacios públicos "privados" (Low, Smith 2006: 21) o espacios semipúblicos. Estos intentos de desplazamiento o prohibición de usos se realizan mediante la potestad regulativa de las Administraciones públicas y como se discute a continuación, contiene diferentes formas y mecanismos. Sin intención de presentar aquí una lista exhaustiva y siendo conscientes de su mutua interrelación, se pueden diferenciar algunas dimensiones claves que se repiten en gran parte del mundo occidental (y en las urbes españolas en particular):

- La 'destrucción de espacio público' por la implementación de 'políticas espaciales neoliberales': La reordenación política y espacial de la ciudad neoliberal se deriva de la toma del poder por parte de las nuevas clases medias e implica la implementación de mecanismos que causan una cada vez más profunda exclusión. Mitchell (1997) atestigua una 'sed de venganza' ejercida mediante la proliferación de leyes que literalmente destruyen el espacio (público), que afecta de forma más acentuada a las personas que precisamente más necesidad tienen de expresarse en sitios abiertos. Por ejemplo, se acumulan diferentes legislaciones que prohiben la estancia de personas indigentes en ciertos espacios 0 , de forma más general, actividades 'diferentes' como mendigar o beber alcohol en espacios públicos. Estas políticas se implementan en detrimento de los individuos más vulnerables que a la vez tienen una mayor necesidad de utilizar el espacio $y$, por ende, necesitarian mayor protección y comprensión. La lógica se basa en la criminalización de actividades discrepantes con el mainstream de la sociedad, con el fin de reordenar los espacios y limpiarlos de individuos poco deseables para los nuevos usuarios que se consideren dignos de la ciudad. Para llegar a ese fin, se suele 'inventar' que las actividades mencionadas tuvieran un peligro para la convivencia. Ciertamente, aquí no se trata de una estrategia de prevención sino de una suposición, de la creación de nuevos delitos con el fin de desplazar un problema social y eliminar su visibilidad, como la criminalización de prácticas culturales tradicionales, bajo la defensa de un uso cívico de la ciudad. 0 lo que es lo mismo, higienizar el lugar. Es el poder disciplinario, que bajo la serie cuerpo-disciplina-instituciones, desarrolla una tecnología de adiestramiento capaz de distribuir a los individuos y a sus actividades en el espacio, fomentándose determinados modelos de conducta ciudadana, donde las apariencias (Goffman 2009) ahora también se interiorizan bajo el panóptico social.

- Las nuevas formas de vigilancia, un tema controvertido por los avances tecnológicos, especialmente cuando se usa en la supervisión de espacios públicos mediante videocámaras. Esta aplicación ha recibido numerosas críticas centradas sobre todo en dos aspectos diferentes: por un lado se aqueja la frecuente ausencia de 'éxito' de las estrategias aplicadas (más allá de la cuestión de cómo definir el supuesto éxito); por otro, se destaca la destrucción de una de las bases de la convivencia urbana moderna, el anonimato, a fuerza de vigilar el espacio público. A pesar de ello, el uso de videocámaras para controlar los espacios 'públicos' urbanos y la grabación de imágenes se han incrementado y 'normalizado' exponencialmente. Mediante la aplicación de tecnologías cada vez más sofisticadas (p.ej., la vigilancia con cámaras de alta precisión utilizada desde helicópteros durante manifestaciones y otros actos de protesta) se intenta además controlar a la población simbólicamente, manifestando una supremacía por medio de la vigilancia tecnológica y demostrando así la hegemonía de las diferentes administraciones públicas para definir de forma arbitraria el límite del comportamiento permitido. El poder público vigila, castiga, normaliza el lugar; y no sólo eso, sino que con estos dispositivos de control genera una sensación de seguridad falseada por un lado, al mismo tiempo que un sentimiento de desconfianza, pánico o miedo por otro. Como nos recuerda Foucault (1990), no se trata de 
que el individuo sea castigado, sino de conseguir que ni siquiera se comporte mal ya que se verá sometido a una visibilidad en el espacio público casi omnipresente (por suerte, aún no omnipotente). Los cuerpos policiales, uno de los principales protagonistas de la planificación urbana de las ciudades (Davis 2001: 9) obtienen una prótesis tecnológica, que les otorga la legibilidad detallada del espacio público como arma de saber-poder. En otras palabras y siguiendo a Foucault (2006), policiar y urbanizar son la misma cosa.

- La proliferación de una estética aséptica: Un sinnúmero de ciudades han introducido políticas urbanas que se concentran en el sentido del gusto de las clases medias y medio-altas, que a su vez viven mayoritariamente en espacios alejados del centro de la ciudad. Como reacción a la competencia urbana que presentan los parques temáticos en la periferia (p. ej., centros comerciales, complejos de ocio), una parte de la reconfiguración urbana se dirige a transformar y comercializar el espacio público. Esto conlleva la proliferación de una estética aséptica que no necesariamente satisface a los habitantes de esos espacios, sino más bien al turista (suburbano) que los visita para entretenerse en su tiempo libre, siendo frecuente el establecimiento de estrategias y condiciones que subordinan la vida urbana exclusivamente al uso comercial, lúdico y estético. Este giro contradice toda idea de participación y apropiación de lugares por los propios habitantes. Al contrario, toda 'diferencia' se excluye con fervor para no molestar a los 'clientes' del espacio; incluso con derivaciones tan irracionales como 'emplear' a cantantes callejeros para re-adjudicarle autenticidad urbana a un espacio controlado, vigilado y políticamente vaciado. El producto de esa gama de políticas deriva en nuevas dinámicas sociales y espaciales que azotan de forma ejemplar a los centros históricos, por ejemplo mediante los planes de renovación y conservación del patrimonio urbano que a su vez incentivan los procesos de gentrificación (Lees et al. 2008). El término responde a la revalorización de capital y se relaciona con el fenómeno de desplazamiento originado por una serie de factores entre los cuales destaca el creciente turismo urbano.

Las tres consideraciones con las que se han explicado algunas de las consecuencias de la espacialidad neoliberal sobre la construcción de la ciudadanía, son la plasmación de los discursos urbanos del poder o la clásica política de la haussmanización (Low, Smith 2006: 25; Harvey 2008), que se encargan de reorganizar el espacio público para favorecer la libre circulación de dinero, mercancias y gente alrededor de los espacios de la ciudad. Estas políticas, nada casuales, convierten a tiendas, bares, etc., en definidores del espacio público y privado capaces de controlar el espacio, convirtiéndolo en un elemento poroso. $Y$ no sólo es el espacio el que se ve transformado, sino que la figura del ciudadano, como espectador, como consumidor, hace de la calle un espectáculo en el sentido más literal. El sesgo que encontramos en todas estas políticas encubre disciplinariedad, economicismo y por supuesto, grandes dosis de clasismo: (i) Disciplinariedad, porque de esta forma se regula al ciudadano, haciéndole entender cómo está bien usado el espacio público y cómo no, dotando de sentido a las tesis de la ciudad dual: la gente sentada en las terrazas es capaz de observar con cínica incredulidad (si no con lástima), a las pobres e incívicas personas que deciden realizar la misma actividad fuera de los márgenes marcados por las fronteras virtuales que territorializan el espacio; (ii) el economicismo, que como ya hemos observado en otros recursos vitales, convierte cada parcela de la vida en objeto mercantilizable. El mecanismo que aplican las políticas urbanas neoliberales sigue los mismos axiomas recurrentes, es decir, articular el incremento del valor del capital mediante la creación de valores de uso (Fourquet, Murard 1978). Y ambas logran nuevamente hacer de la ciudad; (iii) un proyecto de clase. Es en estos espacios precisamente donde los actores expresan su posición en el sistema social, donde se produce el enclasamiento y el desclasamiento (Bourdieu 2000), o lo que es lo mismo, la estratificación social materializada en una fuerte segregación urbana. Nos encontramos atravesados, por tanto, ante un ciudadano como un consumidor de signos. Aparecen constantemente formas de consumo privativas, donde precisamente su carácter excluyente es el que lo convierte en producto comercializable, materializando la desigualdad en la vida cotidiana de las urbes. Porque lo que encontramos en la mayoría de las plazas y calles no son más que espacios usurpados a todos los demás, espacios que en muchos de los casos obstaculizan, incordian, revientan el paisaje urbano, entorpeciendo el escenario público para actividades reificadas y densificadas, de dudosa utilidad social.

De esta forma, el círculo se cierra nuevamente: volvemos a ver a los distintos grupos sociales separados en la misma 
escena pública, en situaciones tan normalizadas que las hacen parecer carentes de importancia, fuera de cualquier análisis científico crítico. Los ciudadanos sentados en las terrazas y los sentados en los bancos de las plazas, los que entran a las boutiques y los que ni las miran -dos modelos de ciudadano, una estratificación social más. Como advierte De Giorgi (2002: 120), la arquitectura de control regula el encuentro impidiéndolo, gobierna la interacción obstaculizándola y disciplina los cuerpos in-visibilizándolos. Estamos ante nuevas estrategias de micro-vigilancia, donde es el propio ciudadano el que ejerce de policía, que como hemos expuesto anteriormente, ayuda en la recuperación de espacios para la revalorización del espacio urbano (Wacquant 2008). Esta lógica no es otra que la perseguida por el neoliberalismo, esto es, el uso de la mercancía como eje reproductor en todas las parcelas de lo social, haciendo del consumo la primera referencia de un campo, el social, hedonista y narcisista. En todo este juego de poderes, el espacio no queda exento de traspirar la misma lógica, el mismo sentido; es más, su expresión más material se reproduce en el "lugar". En un intento de incorporar la sociabilidad en la arquitectura, se pretende pre-diseñar los lugares de encuentro, territorializando las vidas en un intento por gestionar lo impredecible.

Así, la gestión de estos espacios por parte de los poderes públicos son "tecnologías", en el sentido foucaultiano (1990: 48), esto es: tecnologías de producción, para transformar o manipular cosas; tecnología de sistemas de signos, que permiten la utilización de signos, sentidos o símbolos (significaciones); tecnologías de poder, que condicionan la conducta de los individuos, sometiéndoles a determinados fines; y finalmente, las tecnologías del yo, que permiten a dichos ciudadanos efectuar ciertos pensamientos o conductas para alcanzar ciertas metas. Estas categorizaciones que desarrolla Foucault abren varias vías o condiciones de posibilidad: la de ser sometido al gobierno, a comportarse de cierta manera, o la de rechazo o rebelión en potencia. Desde esta segunda vía Foucault entiende que los que se resisten o se rebelan contra alguna forma de poder no deben detenerse en la crítica de una institución, sino que debe ser la racionalidad política misma, la existente, la hegemónica, la que debe ponerse a juicio.

Si desarrollamos a partir de este debate la relación entre producción del espacio, políticas de lugar, ciudadanía y migración, consideramos importante hacer hincapié en dos preguntas para futuras investigaciones. Por un lado, es necesario cuestionar las inherentes relaciones de poder que se manifiestan en los espacios públicos y que perjudican a los más débiles, entre los cuales muchas veces se encuentran los inmigrantes, que reúnen la condición doble de carecer de plenos derechos y de sufrir la exclusión múltiple de los espacios públicos, vigilados y controlados. Por otro lado, es preciso preguntarse por cómo los individuos utilizan los espacios públicos para reconstruir unas relaciones sociales densas, logrando la reapropiación de lugares de los cuales han sido expulsados de forma explícita o, por lo menos, simbólica. Esta perspectiva podría dar lugar a pensar en la contra-manipulación de las políticas de lugar mediante la creación de nuevos significantes y sentidos.

\section{Reflexiones críticas acerCa del COnCEPto DE CIUDADANÍA}

Si ensamblamos ahora la cuestión de la producción del espacio con la cuestión de cómo pensar la ciudadanía, es inevitable constatar, en primer lugar, que la conceptualización de la ciudadanía está viviendo una transformación profunda, dado el nuevo y cambiado rol que tiene el Estado-nación a partir de los procesos de globalización y la profundización de la Unión Europea (Bauböck 2005; Benhabib 2005; Habermas 2009). Por lo que algunas de las teorias tradicionales sobre ciudadanía, como la definida por Marshall (1997) a partir de los derechos civiles, políticos y sociales o a los estudios de Hannah Arendt (1987), que describen las tradicionales dicotomías binarias entre la ciudadanía y la falta de nacionalidad centrándose en los deberes y los derechos de la ciudadanía, precisan de una reconsideración.

En este sentido, se puede destacar que una parte creciente del debate intelectual actual enfatiza la noción de ciudadanía, sobre todo a través de sus expresiones en la vida diaria: por ejemplo, las movilizaciones y las prácticas concretas que se expresan, como hemos mencionado en el apartado anterior, en los espacios públicos y mediante las políticas de lugar (Isin y Wood 1999; Ong 2006). Esto no significa ninguna negación de los derechos de la ciudadanía, constituyentes e indiscutidos, sino más bien una ampliación de las perspectivas teóricas, dando así una respuesta a las múltiples transformaciones que han vivido 
las sociedades post-fordistas, las nuevas relaciones de poder económico y social concentrado en 'ciudades globales' (Sassen 1999) y las respuestas del Estado-nación en un mundo transnacional (Barnett 2003; Low 2004).

Como acentúan Isin y Wood (1999), la ciudadanía se nutre de una multitud de posibilidades de acción. Si se acepta su propuesta de que la ciudadanía es tanto un conjunto de derechos y deberes como una serie de prácticas culturales, económicas y simbólicas, entonces se tendrá que concebir que cambie en el transcurso del tiempo y que se utilice estratégicamente para mantener, reconocer o expandir las exigencias de distintos grupos sociales. Lo que queremos poner en juego es un tipo de ciudadanía -participativa- que implica sobre todo la articulación de identidades colectivas y la transformación del concepto mismo de ciudadanía: desde un derecho constitucional a un acto performativo desarrollado a través de la participación activa en la sociedad y la expresión de reivindicaciones. Concebida de tal manera, la ciudadanía es un objeto en permanente pugna y negociación, una práctica y una capacidad de actuar en un ambiente determinado, que tal como lo proponen Rose (2001) o Wiener (1998), se materializa en identidades (políticas) concretas. A continuación, iremos enlazando las dimensiones de escala e identidad, para continuar con una propuesta alternativa para comprender y reformular el concepto de ciudadanía.

\subsection{Políticas de escala y ciudadanía}

La reconfiguración de la vida política con respecto a la globalización económica y social ha abierto nuevas vías a los movimientos sociales y políticos, a las redes de protesta y resistencia, así como a la solidaridad política con inmigrantes y otros grupos vulnerables (Brown 2008; Routledge 2008). Los actores que traducen sus quejas y reclamaciones en acciones colectivas políticas dependen cada vez más de los diferentes tipos de lazos transnacionales, que permiten el flujo de información o la interacción política a mayor escala (Della Porta y Tarrow 2005; Nicholls 2009). Siguiendo los argumentos de Painter (2008), muchos de los debates dentro de la geografía política se deben a la articulación compleja entre el poder, espacio y lugar. Por ejemplo, las relaciones de poder, las identidades políticas y los actos de la ciudadanía circulan a través de unos límites 'supuestamente' estáticos. Esto tiene consecuencias importantes sobre la forma de pensar la geografía política de la acción colectiva en las sociedades posmodernas. Un enfoque en la construcción relacional de estas identidades a través de las relaciones dinámicas de la actividad política basada en el lugar, puede enriquecer las investigaciones (Pugh 2009). Estas interacciones son esencialmente observadas desde la noción transversal de "políticas de escala" (Delaney y Leitner, 1997; Cox 1998; Jones 1998; Brenner 2000, Sheppard y McMaster 2003). Tomaremos como definición básica la que expresan Leitner et al. (2008: 159), expresando que escala es:

"...una construcción relacional, controvertida y cargada de poder que los actores utilizan estratégicamente con el fin de legitimar o cuestionar las relaciones de poder existentes. En el curso de estas luchas se construyen nuevas escalas, reconfigurándose la importancia de las diferentes escalas. Un elemento central en las políticas de escala es la manipulación de las relaciones de poder y de autoridad."

Es importante tener en cuenta que los debates mencionados establecieron una posición común compartida que introdujo cambios notables hacia posiciones sociales constructivistas. Hasta hace relativamente poco, las políticas de escala se basaban en la extensión geográfica de las prácticas políticas, que se articulaban a escala global, transnacional, nacional, regional y local. Sin embargo, varios autores introdujeron una perspectiva que permite distinguir a la escala como una construcción específica que se relaciona con el actor (Massey 1994; Routledge 2008; Brenner 2001; Leitner et al. 2008) y que lo articula a través de la acción social. A partir de ahí, en las políticas de escala se aplican tres aspectos relevantes, que nos ayudarán a comprender mejor la relación entre escala y ciudadanía:

- En primer lugar, la tradicional vinculación entre protesta e institución del Estado es definida por el concepto de 'nested scales', escalas que van desde el nivel supranacional (europeo, por ejemplo) hasta el nivel local. Por medio de la participación activa en la acción política, se puede relativizar el peso de dichas escalas y, en ocasiones motivar la creación de otras nuevas (Leitner et al. 2008).

- En segundo lugar, los movimientos de protesta emplean con frecuencia una variedad de estrategias haciendo uso de diferentes escalas (desde el activismo transnacional al local). Son los Ilamados 'saltos de escala', un concepto introducido por Smith (1992), como esquema para supe- 
rar las restricciones del localismo (Reid y Sparke 2003; Mamadouh et al. 2004; Leitner et al. 2008). Por ejemplo, en la acción política se puede literalmente saltar escalas y utilizarlas de forma simultánea para lograr por un lado una adhesión local y conectar por otro con un público a la vez local, regional o global -algo que desde la proliferación de las nuevas tecnologías de comunicación se ha hecho patente.

- En tercer lugar; ya que las escalas no son categorías predefinidas, las políticas de escala pueden ser examinadas como un proceso que necesita 'marcos' y esquemas de interpretación para legitimar las actividades y campañas de un movimiento político determinado. Tales esquemas combinan tres objetivos: la construcción de un problema, la identificación de un objetivo para la acción colectiva y la acción de respuesta -ayudando a legitimar los procesos de inclusión y exclusión en los debates políticos (Kurtz 2003).

Sin embargo, este debate acerca de las escalas todavía no es suficiente para relacionar las políticas de escala con una posible redefinición de la ciudadanía. Marsten (2000) y Moore (2008) afirman que una parte importante de las categorías usadas con respecto a las políticas de escala no son fijas, sino construidas socialmente, fluidas y contingentes. Sin embargo, escalas geográficas como 'local', 'nacional' y 'global' se basan en profundas y arraigadas construcciones que se manifiestan en las prácticas cotidianas aunque no sean nada más que 'ficciones intuitivas' (Smith 2003: 35). Aquí, las ideas constructivistas que enfatizan la fluidez y multiplicidad de las categorías sociales, al reconocer que las mismas categorías están reificadas mediante la práctica social, ayudan a rectificar nuestra forma de entender las escalas. En cambio, las ideas que se refieren a las 'nested scales' o a los saltos de escala nos dejan nuevamente ante la ambigüedad de los debates científicos, que vuelven a girar en torno a escalas tradicionalmente construidas (local, urbano, regional, nacional, global, etc.). Asimismo, el uso de las dicotomías, como lo local y lo global, que se aplican normalmente en los discursos sobre las escalas (Lindell 2009), no ayudan demasiado a entender la acción política en sociedades globalizadas, con múltiples procesos de construcción de escalas, mutuamente solapadas e interrelacionadas. Teniendo en cuenta estas apreciaciones, las prácticas escalares y las políticas de escala deberian ser enfocadas de forma alternativa y proponer otras preguntas de investigación distintas a las mencionadas con anterioridad.

En respuesta a esta compleja situación y observando que el uso cotidiano de las escalas como contenedores espaciales es reduccionista, la pregunta es cómo re-conceptualizar la discusión sobre las políticas de escala y enlazarla con los debates de ciudadanía. Con respecto a esto, Jones (2010) propone hacer hincapié en los discursos que construyen espacialidad, como un proceso de distinción y construcción de límites. Tal idea nos puede ayudar a entender las prácticas de los actores sociales en términos escalares (Moore 2008), así como las asimetrías de poder existentes para comprender las relaciones sociales entre y dentro de las escalas (Neumann 2009). Si tomamos entonces en cuenta qué prácticas y qué discursos elaboran, clasifican y narran las escalas (Moore 2008: 221), deberíamos buscar entonces cómo reconocer las relaciones de poder dentro de las categorías escalares. Lo que significa entender (desde las escalas) cómo se comporta la ciudadanía y cómo se utiliza la construcción y el recurso de las escalas para conseguir objetivos políticos específicos. En este sentido, se propone cambiar nuestra orientación hacia las diferentes dimensiones escalares de las prácticas y de los discursos, en lugar de buscar prácticas en las diferentes escalas. Como Toal (2002) señala, las representaciones y prácticas escalares relacionan el poder y las luchas políticas y, como veremos en el capítulo siguiente, esto está estrechamente relacionado con la interpretación constructivista de las políticas de identidad.

\subsection{Políticas de identidad y ciudadanía}

Según las ideas promovidas principalmente desde la perspectiva de los estudios culturales, se destaca que las identidades personales, colectivas y políticas son un constructo social y un posicionamiento relacional que de manera permanente sufre procesos de desestabilización (Hall 1996). Las identidades se crean a través de las prácticas relacionales, las no-relacionales, de las ausencias, de los intersticios y de otras localizaciones continuas en el mundo social, de forma más o menos consciente. El conocer, entender y construir identidades auto-relacionales (el 'yo' y el 'nosotros') implica por lo menos un conocimiento tácito del 'Otro' (el 'tú' y el 'ellos'), como el "no yo", es decir que no forma parte de uno mismo ni del grupo de referencia propio (Massey 2004; Penrose, Mole 2008). En 
consecuencia, la identidad siempre se establece a través de un sistema de diferencias (Hall 1996: 4), 0, en otras palabras: "identity requires difference in order to be, and it converts difference into otherness in order to secure its own self-certainty" (Connolly 2002: XIV). La aceptación de nociones de identidad relacionales, flexibles y desestabilizables conllevan una cadena de comprensiones que son interesantes desde una perspectiva teórica y también política. Siguiendo a Massey (2004), la apreciación de las multiplicidades internas en las identidades implica una perspectiva radical que reta a re-pensar muchos conceptos sociales y espaciales ya dados, como ciudad, región o nación, ya que todos ellos se utilizan como poderosos discursos en el lenguaje común.

Muchos de los debates relacionados con las políticas de identidad y de ciudadanía se originaron alrededor de los procesos de construcción de identidades nacionales y se contextualizaron como identidades culturales, apareciendo como construcciones históricamente contingentes. Las identidades nacionales siguen siendo un esquema importante de expresión de la adhesión colectiva a los grupos sociales construidos, pero el foco de atención se ha desplazado hacia representaciones alternativas para estudiar cuestiones de identidad. Teóricos poscoloniales como Bhabha (2008) respaldan la tesis de que los vínculos culturales se producen de manera performativa. En consecuencia, enfocan su análisis de las identidades en cómo los códigos culturales naturalizados se exponen, con el fin de desestabilizarlos. Sin embargo y a pesar de una variedad de estudios acerca de un mundo social 'híbrido', la cuestión de cómo se usan estratégicamente los conceptos culturales esenciales, por ejemplo, en la resistencia política o conflictos políticos, no ha sido abordada con la profundidad necesaria.

En relación al debate mencionado es importante, en primer lugar, destacar que las identidades colectivas, al igual que las escalas en el apartado anterior, no pueden ser pensadas sin las relaciones de poder existentes, que siempre son una expresión de o una protesta en contra de ellas. Consideramos que deben ser evaluadas como una representación motivada por el interés político basado en un fundamento emocional compartido para activar los procesos de integración del grupo mismo. En este aspecto destaca explícitamente el significado de las políticas de identidad y de construcción de ciudadanía que promueven innovaciones sociales y po- líticas, desafiando los procesos tradicionales. Esto pasa al margen del hecho de que todos los procesos de acción política necesitan implícitamente fijaciones temporales de las identidades fluidas y flexibles. El entorno globalizador está permitiendo que las actividades políticas generen una gran variedad de apropiaciones y de significantes de carácter transnacional, donde las cuestiones de la identidad cultural juegan un papel decisivo. Si se entienden las políticas de identidad como representaciones de significados sociales y espaciales, se abre un abanico de coaliciones políticas y una base compartida para la acción concreta en conflictos políticos que trascienden lo local o a la comunidad. Como lo destaca Nicholls (2009), los actores que participan en la política y en sus conflictos habituales proyectan identidades esenciales que silencian la multitud de diferencias internas que puede provocar su participación -tanto a nivel individual como para el colectivo que representan. Castiglione (2009) se refiere a eso mediante el uso del término de "identidad política", que incluye dos nociones distintas: Por un lado, la manera en que la acción política y las instituciones contribuyen al proceso de identificación y diferenciación, abriendo la posibilidad de extender el sentimiento de pertenencia simultánea a diferentes grupos y formaciones sociales; y por otro, abarcando el sentido de lealtad hacia la comunidad política para facilitar la identificación y la defensa del grupo contra amenazas externas.

De forma parecida a los debates anteriores acerca de las políticas de lugar y de escala, la cuestión central en este apartado ha sido la de revisar conceptualmente el uso de las identidades. Para ello, se ha propuesto relacionar las políticas de identidad con las dimensiones escalares de las prácticas y de los discursos, o, en otros términos, responder a la pregunta de cómo se construyen las escalas mediante las políticas de identidad. Si pensamos integrar las políticas de identidad en una propuesta alternativa de ciudadanía que pueda servir para acercarnos al análisis de los conflictos en las sociedades migrantes, es necesario fijarse en cómo se utilizan estratégicamente las políticas de identidad en luchas y disputas, para lo que se deben relacionar las políticas de lugar con las políticas de identidad.

\subsection{Ciudadanía y la constitución del ciudadano activista}

A partir de las reflexiones entabladas hasta el momento, es posible desarrollar una respuesta teórica alternativa que

ARBOR Vol. 188755 mayo-junio [2012] 515-527 ISSN: 0210-1963

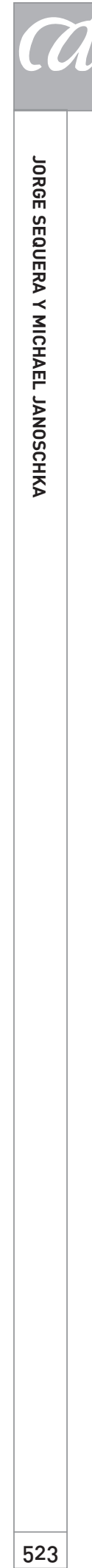


se basa fundamentalmente en las variadas y diferenciadas conceptualizaciones de ciudadanía que ofrece la teoría social actual, para analizar las políticas de ciudadanía desde la articulación de las políticas de identidad, de escala y de lugar. En este sentido, nos interesa explícitamente interpretar la construcción social del concepto de ciudadanía desde su dimensión conflictiva, apuntando precisamente a los conflictos políticos que han hecho emerger nuevos actores, sitios y escalas de ciudadanía (Isin 2009). En estos actos, afirmamos, los nuevos actores surgen como sujetos reivindicativos, a partir de la emergencia de nuevas escalas y recurriendo a las políticas de lugar. Estamos ante un proceso paulatino que insta a remplazar las inherentes relaciones de poder entre ciudadano y Estado, mediante una ciudadanía que ahora también se puede entender e interpretar a partir de los actos reivindicativos que efectúan los individuos (Isin 2008). Estos 'actos de ciudadanía' tienen como génesis las rupturas, el desorden y la desviación, lo que desde las instituciones sería considerado como anomía política, pero que en realidad es pura deconstrucción, es decir, un proceso constituyente de nueva ciudadanía. Se trata por tanto de explorar las formas en las cuales se está creando y recreando la ciudadanía como un concepto relacional (Aradau et al. 2010). Esto significa que las expresiones [los actos], los lugares [los sitios] y las escalas de identificación y ciudadanía pueden variar de forma substancial y no necesariamente responden a las escalas de organización de la administración y de la vida pública. Así, podemos empezar a pensar de nuevo esa relación, para lo que nos apoyaremos en modelos alternativos para repensar la ciudadanía.

Entre otros, Seyla Benhabib (2005) defiende que la ciudadanía debería pensarse sin el nexo 'Estado-nación', y Stephens (2010) desarrolla una conceptualización de 'ciudadanía sin comunidad' que niega la necesidad de pensar los sitios y los actos de ciudadanía mediante el recurso a las autoridades estatales, defendiendo pensar los ciudadanos [los marginados, los forasteros, los extranjeros] como seres no definidos de antemano. Al contrario, se trata de intentar entender los procesos y los actos mediante los cuales los sujetos se constituyen como ciudadanos (Isin y Nielson 2008). Dentro de ese panorama, Isin (2009) define los 'actos de ciudadanía' como la expresión de los individuos que necesitan ser oídos por su condición de desigualdad estructural. En los momentos de actuación, el actor produce una ruptura [intencionada o no inten- cionada], mediante la cual se crea una nueva escena, estableciéndose nuevas disposiciones que introducen la posibilidad de nuevas rupturas en el poder hegemónico de la maquinaria, creándose nuevos 'espacios de ciudadanía' (Tamayo 2006). En este sentido, Isin (2009: 383) define los actos de ciudadanía como:

"aquellos actos que transforman las formas (orientaciones, estrategias, tecnologías) y los modos (ciudadanos, extranjeros, los marginados, los forasteros) de ser político albergando nuevos actores, como a los ciudadanos activistas (esto son los demandadores de derechos), a través de la creación y la transformación de sitios y la expansión de las escalas, como nuevos actores".

A partir de esa definición es posible defender que la ciudadanía se expresa a través de las luchas contra-hegemónicas de individuos o distintos grupos en un proceso continuo de formación y reformulación. Consecuentemente, los actores, las escalas y los sitios de ciudadanía emergen mediante las reivindicaciones de reconocer construcciones de identidad distintas a las hegemónicas. Como tal, podemos entonces re-significar el término de ciudadanía para politizarlo y aplicarlo en el análisis de acción colectiva mediante los procesos de formación de identidad. En conclusión, examinar a la ciudadanía a través de la constitución de nuevos actores puede inspirar las investigaciones relacionadas con las luchas subalternas y contra-hegemónicas. Para ello, consideramos que se puede enfocar desde tres aspectos fundamentales: Primero, interpretar los actos de ciudadanía a través de sus consecuencias, en el que los sujetos devienen, a partir de los nuevos escenarios creados, ciudadanos activistas. Segundo, relacionar los actos de ciudadanía con las demandas urbanas, por ejemplo mediante los distintos mecanismos con los que los actores cuestionan simultáneamente las reconfiguraciones del espacio urbano en el capitalismo neoliberal. Tercero, como los actos de ciudadanía no respetan necesariamente las leyes ni necesitan regirse por la aplicación de las reglas jurídicas (Isin 2008), se pueden analizar las apropiaciones subversivas de los espacios como cuadro analítico para la interpretación de los actos no conformistas de protesta y contestación.

Como resalta Tamayo (2006: 32), las luchas por los derechos se han convertido en el principal motor del cambio político y social, ya que es a través de las luchas simbólicas 
que los sujetos se transforman en ciudadanos activistas, mediante apropiaciones ciudadanas del espacio público, en lo que define como 'espacios de ciudadanía'. Estos espacios ciudadanos son a la vez objetivos (por la dimensión física) y subjetivos (por la dimensión de la comunidad), complejizando el concepto de ciudadanía al tratar de articularlo con el espacio y el poder. Esta perspectiva integra lo espacial en la re-significación de la ciudadanía como el resultado de luchas sociales en la sociedad migrante.

\section{Conclusiones}

En el debate que hemos presentado en este trabajo, hemos defendido que las conceptualizaciones referentes a las políticas de lugar, escala, identidad y ciudadanía deben encontrar nuevas preguntas con las que acercarse de forma constructivista a los debates recientes. Para ello, hemos dado respuesta a algunas de las ideas del 'giro espacial' en las ciencias sociales, que dotan a la espacialidad de un papel central (Pugh 2009) en los marcos de análisis. Refi- riéndonos a las políticas de lugar, a las políticas de escala, a las políticas de identidad y a las políticas de ciudadanía hemos establecido un marco que puede ayudar al estudio de conceptos como la identidad, la pertenencia y la ciudadanía bajo su espacialidad inherente. En este sentido, hemos repensado el concepto de ciudadanía, introduciendo cambios epistemológicos en la forma en que se teoriza comúnmente el lugar, la escala y la identidad, es decir, observándolos desde los propios actos concretos, centrados en las políticas de lugar, las políticas de escala y las políticas de identidad. Lo que nos ha llevado a ver ciudadanía, escalas e identidades a través de los "actos de ciudadanía", donde todos los actos de resistencia y apropiación subversiva del entorno, permiten re-formular y re-interpretar las escalas y la identidad a partir de su específica espacialidad. Este cuadro teórico puede resultar como programa analítico para el estudio de las relaciones conflictivas en las sociedades globalizadas, con múltiples procesos de reconfiguración social, económica y política, que contienen procesos de expulsión (de inmigrantes y grupos sociales en situaciones de vulnerabilidad) por una mala, intencionada o vaga interpretación del concepto de ciudadanía.

\section{NOTAS}

* Este artículo se ha ido desarrollando en el marco de los proyectos de investigación "Integración, Participación y Justicia social - Ejes normativos de las Políticas Migratorias", financiado por el MICINN (FFI2009-07056) y "NEOLIBERAL_CITI - Re-framing urban neoliberalism and neo-liberal citizenship", financiado por la Comisión Europea (PERG-08-GA-2010-277115). Una versión preliminar fue presentada y discutida en el Seminario Permanente de Investigación que se organiza en el marco del proyecto en el CCHS-CSIC, por lo cual se agradece el estímulo recibido durante ese y otros debates efectuados.

1 Por sociedad migrante entendemos a una sociedad entera atravesada por múltiples lugares y escalas que configuran identidades y ciudadanias complejizadas. Hacemos hincapié en hablar de "migrantes" para des-diferenciar la entrada (in-migración) de la salida (e-migración), ya que la condición de ciudadanía que proponemos alberga otras escalas diferentes a las creadas por el Estado-nación. La desarticulación de la soberanía del Estado y de sus habitantes, pasa por comprender la ciudadanía más allá de sus límites jurídico-formales.

\section{BIBLIOGRAFÍA}

Alonso, L. (2004): "Las políticas del consumo: transformaciones en el proceso de trabajo y fragmentación de los estilos de vida", en Revista Española de Sociología, 4(1): 7-50.

Aradau, C.; Huysmans, J. y V. Squire (2010): "Acts of European Citizenship: A Political Sociology of Mobility", en 
Journal of Common Market Studies, 48: 945-965.

Aramburu, M. (2008): "Usos y Significados del Espacio Público", en Arquitectura, Ciudad y Entorno, 3(8): 143-150.

Arendt, H. (1987): "La decadencia de la nación-Estado y el final de los derechos del hombre", en Los orígenes del totalitarismo, vol. 2. Madrid: Alianza, 392-438.

Barnett, C. (2003): Culture and Democracy, Edimburgo: Edinburgh U.P.

Bauböck, R. (2005): "Expansive Citizenship", Political Science \& Politics, 38: 683-687.

Benhabib, S. (2005): Los derechos de los otros, Barcelona: Gedisa.

Bhabha, H. (2008): "Locations of Culture", en Khagram, S. y P. Levitt (eds.): The Transnational Studies Reader, Londres/ Nueva York, 333-338.

Borja, J. (2003): La ciudad conquistada, Madrid: Alianza.

Bourdieu (2000): Esquisse d'une théorié de la pratique, Paris: Points.

Brenner, N. (2000): "The Urban Question", en International Journal of Urban and Regional Research, 24: 361-378.

Brenner, N. (2001): "The limits to scale?", en Progress in Human Geography, 25: 591-614.

Brown, M. (2008): "Working Political Geography Through Social Movement Theory", en Cox, K.; Low, M. y J. Robinson (eds.): The SAGE Handbook of Political Geography, Londres: Sage, 285-303.

Castiglione, D. (2009): "Political identity in a community of strangers", en Checkel, J. y P. Katzenstein (eds.): European Identity, Cambridge: Cambridge U.P., 29-51.

Connolly, W. (2002): Identity|Difference, Minneapolis: University of Minnesota Press.

Cox, K. (1998): "Spaces of dependence, spaces of engagement and the poli- tics of scale", en Political Geography, 17: 1-23.

Davis, M. (2001): Más allá de Blade Runner Barcelona: Virus.

De Giorgi, A. (2002): El gobierno de la excedencia, Madrid: Traficantes de sueños.

Delaney, D. y H. Leitner (1997): "The political construction of scale", en Political Geography, 16: 93-97.

Delgado, M. (2011): El espacio público como ideología, Madrid: Los libros de la Catarata.

Della Porta, D. y S. Tarrow (2005): "Transnational Processes and Social Activism", en Della Porta, D. y S. Tarrow (eds.): Transnational Protest \& Global Activism, Boulder: Rowman \& Littlefield, 1-20.

Foucault, M. (1990): Tecnologías del yo y otros textos afines, Barcelona: Paidós.

Foucault, M. (2006): Seguridad, territorio, población, Buenos Aires: FCE.

Fourquet, Fy L. Murard (1978): Los equipamientos del poder, Barcelona: Gustavo Gili.

Goffman (2009): La presentación de la persona en la vida cotidiana, Buenos Aires: Amorrortu.

Habermas, J. (2009): ¡Ay, Europa!, Madrid: Trotta.

Hall, S. (1996): "Introduction: Who Needs 'Identity'?", en Hall, S. y P. Du Gay (eds.): Questions of Cultural Identity, London, 1-17.

Harvey, D. (1996): Justice, Nature \& the Geography of Difference, Cambridge/ Oxford: Blackwell.

Harvey, D. (2008): París, capital de la modernidad, Madrid: Akal.

Isin, E. (2008): "Theorizing Acts of Citizenship", en Isin, E. y G. Nielsen (eds.): Acts of Citizenship, Londres: Palgrave Macmillan, 15-43.

Isin, E. (2009): "Citizenship in flux", en Subjectivity, 29: 367-388.
Isin, E. y G. Nielsen (2008, eds.): Acts of Citizenship, Londres: Palgrave Macmillan.

Isin, E. y P. Wood (1999): Citizenship and Identity, Londres: Sage.

Janoschka, M. (2010): "Prácticas de ciudadanía europea y participación política", en Arbor, 186 (744): 705-719.

Janoschka, M. (2011): "Geografias urbanas en la era del neoliberalismo", en Investigaciones Geográficas, 76: 118-132.

Jones, R. (2010): "The spatiality of boundaries", en Progress in Human Geography, 34: 263-267.

Kurtz, H. (2003): "Scale frames and counter-scale frames", en Political Geography, 22: 887-916.

Lees, L.; Slater, T. y E. Wyly (2008): Gentrification, Londres: Routledge.

Leitner, H.; Sheppard, E. y K. M. Sziarto (2008): "The spatialities of contentious politics", en Transactions of the Institute of British Geographers, 33: 157-172.

Lepofsky, J. y J. Fraser (2003): "Building Community Citizens", en Urban Studies, 40: 127-142.

Lindell, I. (2009): '"Glocal' movements: place struggles and transnational organizing by informal workers", en Geografiska Annaler: Series B, Human Geography, 91: 123-136.

Low, M. (2004): "Cities as Spaces of Democracy", en Barnett, C. y M. Low (eds.): Spaces of Democracy, Londres: 129-146.

Low, S. y N. Smith (2006): The politics of public space, Londres: Routledge.

Mamadouh, V.; O. Kramsch y M. van der Velde (2004): "Articulating local and global scales", en Tijdschrift voor economische en sociale geografie, 95: 455-466.

Marshall, T. H. (1997): "Ciudadanía y clase social", en REIS, 79: 297-344.

Massey, D. (1994): Space, Place and Gender, Minneapolis: University of Minnesota Press. 
Massey, D. (2004): Geographies of Responsibility, en Geografiska Annaler, 86: 5-18.

Mitchell, D. (1997) The Lie of the Land, Minneapolis: University of Minnesota Press.

Moore, A. (2008): "Rethinking scale as a geographical category", en Progress in Human Geography, 32: 203-225.

Neumann, R. (2009): "Political ecology: theorizing scale", en Progress in $\mathrm{Hu}$ man Geography, 33: 398-406.

Nicholls, W. (2009): "Place, networks, space", en Transactions of the Institute of British Geographers, 34: 78-93.

Ong, A. (2006): Neoliberalism as Exception: Mutations in Citizenship and Sovereignty, Durham/Londres: Duke U.P.

Painter, J. (2008): "Geographies of Space and Power", en Cox, K.; Low, M. y J. Robinson (eds.): The SAGE Handbook of Political Geography, Londres: Sage, 57-72.

Penrose, J. y R. Mole (2008): "Nation-States and National Identity", en Cox, K.; Low, M. y J. Robinson (eds.): The SAGE Handbook of Political Geography, Londres, Sage, 271-283.
Pugh, J. (2009): "What are the consequences of the 'spatial turn' for how we understand politics today?", en Progress in Human Geography, 33: 579586.

Reid, C. y M. Sparke (2003): "The Cultural Geography of Scale", en Anderson, K. et al. (eds.): Handbook of Cultural Geography, Londres: Sage, 485-497.

Rose, J. (2001): "Contexts of Interpretation", en The Canadian Geographer 45: 474-493.

Routledge, P. (2008). "Transnational Political Movements", en Cox, K.; Low, M. y J. Robinson (eds.): The SAGE Handbook of Political Geography, Londres: Sage, 335-349.

Sassen, S. (1999): La ciudad global, Buenos Aires: Eudeba.

Sassen, S. (2003): Contrageografías de la globalización, Madrid: Traficantes de sueños.

Sheppard, E. y R. McMaster (2003): Scale \& Geographic Inquiry, Oxford: Blackwell.

Smith, N. (1992): "Geography, difference and the politics of scale", en Doherty, J.; Graham, E. y M. Malek (eds.):
Postmodernism and the social sciences, Londres: Macmillan, 57-79.

Smith, R. (2003): "World city actor-networks", en Progress in Human Geography, 27: 25-44.

Staeheli, L. (2011): "Political geography: Where's citizenship?", en Progress in Human Geography, 35 (3): 393-400.

Stephens, A. (2010): "Citizenship without community", en Citizenship Studies, 14: 31-46.

Tamayo, S. (2006): "Espacios de ciudadanía, espacios de conflicto", en Sociológica, 21 (61): 11-40.

Tilly, Ch. y S. Tarrow (2007): Contentious politics, Boulder: Paradigm Publishers.

Toal, G. (2002): "Theorizing practical geopolitical reasoning", Political Geography, 21: 601-628.

Wacquant (2008): "Relocating Gentrification", en International Journal of Urban and Regional Research, 32.1: 198-205.

Wiener, A. (1998): 'European' Citizenship Practice. Building Institutions of a Non-State, Oxford: Oxford U.P. 